\title{
HEALTH PROBLEMS OF EPOXY RESINS AND AMINE-CURING AGENTS
}

\author{
BY \\ L. B. BOURNE, F. J. M. MILNER, and K. B. ALBERMAN \\ From the Cossor Group of Companies and Scientific Pharmacals Ltd.
}

(RECEIVED FOR PUBLICATION AUGUST 18, 1958)

\begin{abstract}
Epoxy resins were first introduced about 10 years ago. Toxic effects, particularly dermatitis, have been frequently described. An investigation into the possible causes of pathological sequelae following the use of epoxy resin/amine mixtures has been undertaken. The cause of most cases of dermatitis and sensitization appears to be uncombined amine which is present in recent mixtures and persists in hardened resin for long periods. The results of experiments with two of the most commonly used resin/amine mixtures confirm this. Cold-cured resins are more dangerous and remain so even when hardened. A simple theory is suggested for the mechanism of the reaction between epoxy resins, amines, and biological systems. This theory leads logically to the handling precautions outlined.
\end{abstract}

There is a growing literature on the effects of epoxy resins, curing agents, hardeners, and the combinations of these resins with other chemical compounds sufficient to warrant an examination of the possible causes of the difficulties which have resulted from the manufacture and use of these substances. These resins were first introduced into England about 10 years ago from Switzerland. As originally conceived in 1936 the resins were an attempt to produce a compound capable of being used in a mould for dental work without shrinking when polymerized. According to Narracott (1953), I. G. Farbenindustrie first disclosed that epoxy resins with the addition of amines could form hardenable products satisfactory for cementing and bonding. Soon after this, Custans in Switzerland found that amines could cure epoxy resins and the CIBA Company have widely patented this method. Most of the hazards may be avoided by good engineering installations and " no touch" technique modified systems and new materials. There are few reports of preliminary work on the toxicity of the chemicals, and furthermore the position is complicated by international patent problems which have encouraged some manufacturers of the primary materials to be reticent about giving this information.

\section{Chemistry of the Epoxy Resins}

Essentially the epoxy resins fall into the category of thermo-setting materials, although, in many cases, the system employed may be classified as "cold curing ". This is meant to indicate the absence of applied heat rather than the absence of heat altogether as in all these systems heat is generated in the chemical reactions which occur. Epoxy resins are the reaction product of two chemicals, epichlorohydrin and diphenylolpropane. This is a condensation reaction which results in long chains which have the generalized formula:<smiles>CC(C)(CC(O)COC1CCC(C(C)(C)C2CCC(OCC3CO3)CC2)CC1)C1CCC(C2(C)CCC(OCC3CO3)CC2)CC1</smiles>

but these are not always applicable in the wide field of use and also depend to a large extent on the quantities of raw materials used.

Little is known of the systemic effects in man of many of the newer chemicals used in these processes, as much experimental work is being carried out with
In this formula " $\mathrm{n}$ " indicates a number of repeated units of the form contained in the bracket.

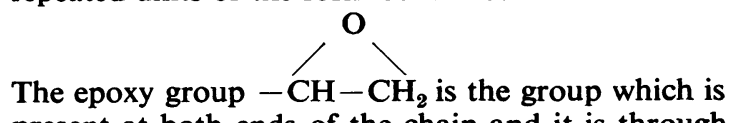
present at both ends of the chain and it is through 
this and the pendant hydroxyl, $-\mathrm{OH}$, groups that reaction occurs. Both these groups are chemically reactive, a fact which is of importance when considering the physiological properties of the resins themselves. The activity is, however, of a low order and the resins are stable to a large extent, indicating that there is little interaction of the epoxy and hydroxyl groups. There are a number of possible variations of this product, each designed to impart improved properties in one or more directions, but the generalized form is sufficient for this discussion. These forms vary from fairly low viscosity liquids to fusible solids and may contain additions such as solvents or plasticizers. They are readily attacked by chemicals and are readily soluble in a variety of solvents.

The low viscosity resins are composed of short chains, i.e., " $\mathrm{n}$ " in the above formula is comparatively small. It will be evident, however, that this type of resin will have more epoxy groups since every chain has one at each end. The more viscous or solid resins have longer chains and correspondingly fewer free epoxy groups are present. This will have a bearing on the physiological properties from two aspects. First, the less viscous resins are more readily miscible with or soluble in other liquids, which may include such physiological fluids as sweat. Secondly, if there is any medical objection to the epoxy group this will be more pertinent in the case of the low molecular weight resins than the higher.

Further, the passage of a low molecular weight or short-chain polymer through a permeable or semi-permeable membrane will be easier than with the longer chains. This applies also in the case of the curing agents discussed below. It should be noted however, that low viscosity in an epoxy resin may not be inherent in the resin itself but may be due to the presence of a solvent or plasticizer.*

In all cases these resins are converted to hard, infusible solids by the addition of certain substances which are generally termed "curing" agents or

* Chemically the epoxy resins are homologues of the diglycidyl ether of diphenylolpropane

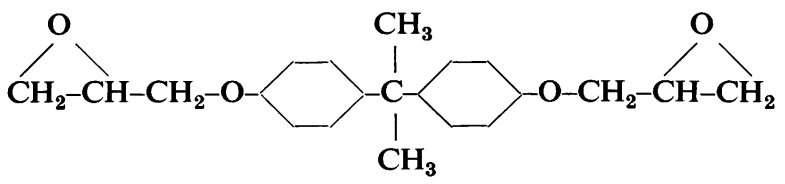

which, it can be seen, has the generalized formula given earlier, " $n$ " here being $O$. The commercial resins contain proportions of this and other straight chains with varying values of " $n$ " as well as some branched chain molecules. The simple diglycidyl ether, however, is representative of the epoxy structure and for this reason has been used in some medical studies on the epoxy resins (Hine, Kodama, Wellington, Dunlop, and Anderson, 1956). hardeners. Some curing agents will react without the addition of heat and are designated as "cold" curing while others require the application of external heat and are designated as "hot curing".

In the case of cold-curing reactions, although an infusible solid can be produced without heat, the best properties of the resin system are usually developed by applying heat to the cured material, a process which is generally referred to as "post curing ".

Curing of the epoxy resin is brought about by a chemical splitting of the epoxy ring which leads to linkages between the long-chain molecules. This linking takes place in such a way that a threedimensional lattice is built up which is chemically very stable and unreactive and which has excellent electrical and mechanical properties. The cured resins are extremely resistant to all solvents. These properties have led to the widespread use of these resins for adhesives, laminating, embedding or potting of electronic circuits, and in paint formulations. They are now also being used quite widely in the manufacture of tools and, for example, press tools. The final properties of the cured system depend to a large extent on the curing agent used and the method of cure. The resin worker is influenced more by process and product considerations in his choice of system than by medical considerations.

The classification of curing agents as hot or cold curing is of value practically, but medically the chemical classification of the materials is more important and it is in this way that we shall consider them. The most commonly used curing agents belong to the class of chemicals known as amines, and next to these in use are the acids and acid anhydrides. Chemical variants of these two groups are becoming prominent due to efforts within industry to produce safer handling materials but the reactivity of these materials still rests in the same functional chemical group. One other group of materials is rapidly gaining wide acceptance on account of their many advantages as curing agents, coupled with their relatively much safer handling. These are the polyamides. Each of these groups will be considered separately.

Amines.-Amines fall into three groups and have the following generalized formulae:-

$\begin{array}{lll}\text { Primary amine .. } & \ldots & \mathbf{R N H}_{2} \\ \text { Secondary amine } & \ldots & \mathbf{R}_{2} \mathbf{N H} \\ \text { Tertiary amines } & \ldots & \mathbf{R}_{3} \mathbf{N}\end{array}$

" $R$ " in these formulae represents any organic group, which may be a straight chain, in which case the amine is referred to as aliphatic, or it may be a ring compound, in which case the amine is referred to as aromatic. Aliphatic and aromatic amines of all 
$\begin{array}{lllllllllll}\text { Ethylene diamine } & \ldots & \ldots & \mathrm{NH}_{2}-\mathrm{CH}_{2}-\mathrm{CH}_{2}-\mathrm{NH}_{2} & \ldots & \ldots & \ldots & \ldots & \text { primary aliphatic }\end{array}$ Diethylene triamine $\quad \ldots \quad \ldots \quad \mathrm{NH}_{2}-\mathrm{CH}_{2}-\mathrm{CH}_{2}-\mathrm{NH}-\mathrm{CH}_{2}-\mathrm{CH}_{2}-\mathrm{NH}_{2} \quad \ldots \quad$. $\quad$. Triethylene tetramine .. $\quad . \quad \mathrm{NH}_{2}-\mathrm{CH}_{2}-\mathrm{CH}_{2}-\mathrm{NH}-\mathrm{CH}_{2}-\mathrm{CH}_{2}-\mathrm{NH}-\mathrm{CH}_{2}-\mathrm{CH}_{2}-\mathrm{NH}_{2} \quad$ ", ", Dimethylamino propylamine .. $\mathrm{CH}_{3}$

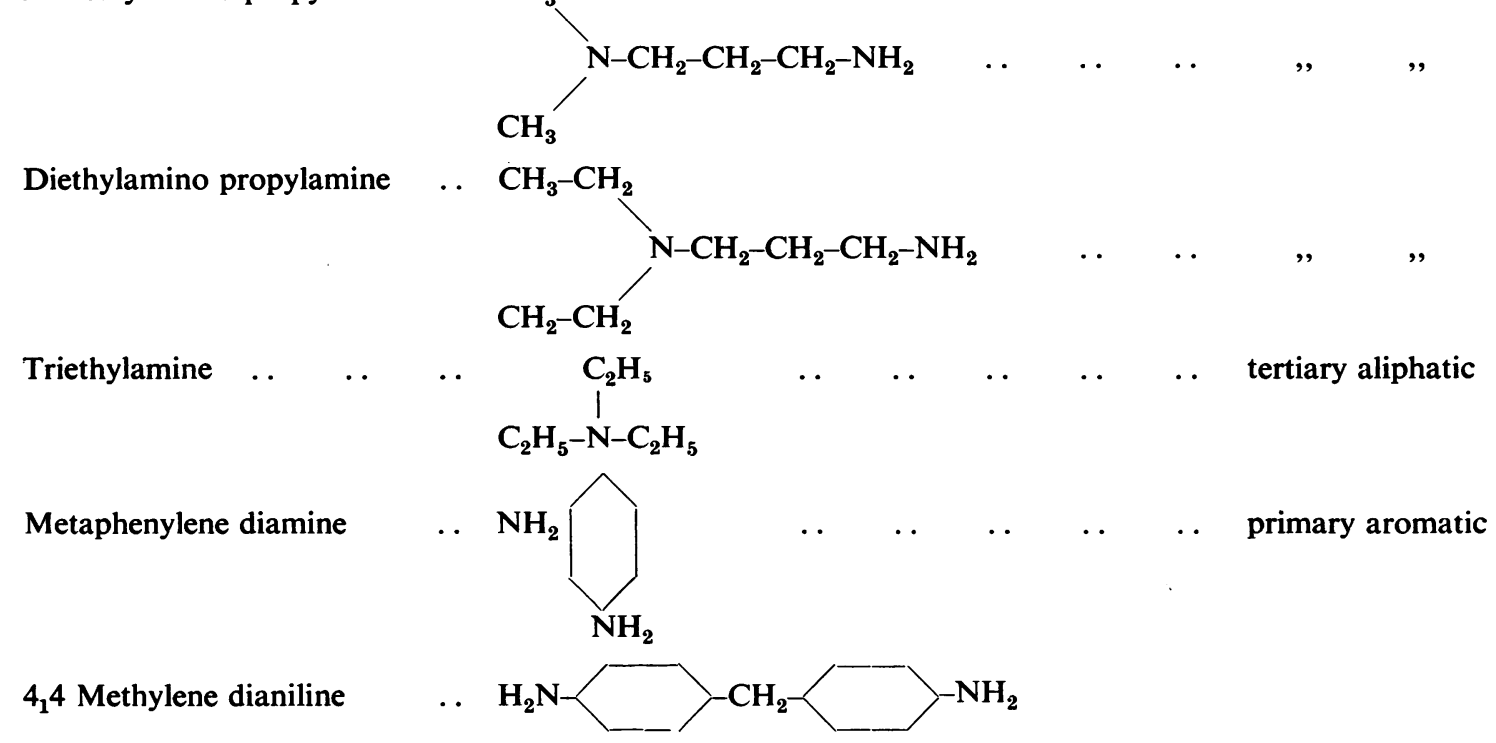
Piperidine<smiles>C1CCNCC1</smiles>

types can be used as curing agents for epoxy resins. The most commonly used are listed above.

It should be noted that with the exception of piperidine these compounds contain two or more amine groups and are usually referred to as " polyamines".

This list is by no means exhaustive and takes no account of the many variants based on these and other amines which are also available. The amines are, for the most part liquid, although some are solid, e.g., metaphenylene diamine, as is also the case with some of the chemical variants available. In the case of these solid materials, however, they are either brought to a liquid state by heating for incorporation into the resin, or alternatively they are dissolved into the hot resin. It should also be noted in this respect that solid resins have to be brought to the liquid state by heating for incorporation of the curing agent.

The liquid amines in the main are highly volatile, pungent materials which may fume profusely in the air and are soluble in water. They are strongly alkaline and highly reactive and all have physiological hazards. Certain of the modified amines or amine adducts, e.g., amine oxide type adducts which are of use in the adhesive and laminating fields, are claimed to be less irritating than the normal amines and for this reason have been designated as having "minimum irritation potential" or M.I.P. It must be stressed, however, that these materials are still essentially amine in character, e.g. :

Bis-hydroxy ethyl diethylene triamine<smiles>OCCNCCNCCNCCO</smiles>

Organic Acids and Acid Anhydrides.-Organic acids have not found much use as curing agents for epoxy resins but may be employed and are best 
mechanically. In the case of liquid hardeners, the volume corresponding to the weight may be calculated and measured out using volumetric equipment such as a tilt measure which can be preset to deliver a given volume. During all these operations the operator can be exposed to physical contact with both resin and curing agent and also to any vapours arising from them.

After mixing, the resin system is used in various ways. As an adhesive the mixed resin is applied to the surfaces being bonded, an operation which can involve considerable danger to the hands. In laminating the resin may be smeared over a moulding between layers of the appropriate laminating material. This is one of the most dangerous operations for contaminating the hands and it is perhaps fortunate that the high price of epoxy resins, among other things, has prevented their wide adoption for this type of work. In potting work the mixed resin is poured into a mould, usually metal but sometimes polythene or other suitable plastic, which may have been previously heated. With reasonable care, the hands need not be in contact in this operation, but there is considerable danger from vapour, especially using hot systems.

In all these applications the system may be hot- or cold-cured. Laminating systems are normally coldcured, but if heat is required it is normally applied by means of heaters built into the mould. Pressure may be used in this case also, and this may be applied by means of a vacuum bag technique. In this case any vapour coming from the system will be sucked off through the vacuum pump and may be discharged at a point quite remote from the mould. Adhesive and casting systems are also hot- or coldcured. For cold-curing the system is simply left aside for the appropriate time for curing to take place. Hot-curing in both cases is normally carried out in an oven. In this case, unless the oven is fitted with efficient extraction, there may be a considerable concentration of volatile fumes in the oven. Operators opening such ovens will be exposed to these hot vapours. It is important that extracted fumes from curing ovens are discharged clear of any employees.

When cure is complete the product is removed from the oven and/or the mould. At this stage the system is handled. This should be a safe procedure, but in certain cold systems a film of unreacted curing agent may be present on the surface when it comes in contact with the air. Further, cured systems may be subjected to machining, an operation which is generally regarded as safe, but in view of the possibility of unreacted curing agent being still present, this is open to question and will be discussed again later.
On the chemical side it should be noted also that many modifying agents such as fillers and plasticizers may be incorporated into the resin system, particularly in casting and laminating work. Some of these, such as mica, silica flour, and fibreglass materials, may have health hazards in themselves, to which appropriate attention should be given.

One last application which has not been discussed above is the use of epoxy resins in paints. So far no serious trouble has been encountered in this field, probably due to the low reactivity of the hardeners employed, but care should be exercised since essentially chemically active substances are involved, and in application these are present in solvents which may readily penetrate the skin, carrying resin and curing agent with them. A recent addition to this group is a pitch-epoxy resin surface coating which, it is claimed, is cold cured with normal amine curing agents. A solution of diethylene triamine in secondary butanol is claimed to give good results. This system is being recommended for brush or spray application to such items as pipes and tanks. As the amine hardeners are known as a serious dermatitis risk, and in this case they are present in a volatile solvent, extensive precautionary measures will undoubtedly be necessary, particularly with spray applications.

\section{Experimental}

It was decided to investigate the possible cause of dermatitis in the more commonly used mixtures particularly with regard to the amounts of amine used, as all suppliers recommend the provision of larger amounts of these than appears absolutely necessary to harden the resin. As one of the commonly used resins contains an unspecified plasticizer, this may have been of considerable influence in increasing the risk. It is also generally accepted that some of the many by-products which may result from these combinations may be the cause of some cases of dermatitis, but from previous experience it was likely that unused amine could be the most potent hazard.

Resin triethylene tetramine (" $D$ "/T.E.T.) mixtures were prepared under normal factory conditions. These were then de-aerated until no bubbles were seen to emerge from the mixtures. Small amounts were then spread on microscope slides. The $p \mathrm{H}$ of these mixes is about 10 to 11 . Some of the slides were allowed to harden in air, others were placed in ovens at $60^{\circ} \mathrm{C}$. It was found that all air-dried mixtures were of groundglass appearance whereas those stoved were much clearer, some being transparent. On microscopic examination the ground-glass appearance (Fig. 1) was due to circular bubbles of two types, some appearing to have a denser opaque centre and others fairly clear as if gaseous (Fig. 2). As resin D is known to contain a plasticizer (possibly di-octylphthalate), resin from another supplier containing no plasticizer was mixed with T.E.T. and examined after stoving; the result was a film 
mechanically. In the case of liquid hardeners, the volume corresponding to the weight may be calculated and measured out using volumetric equipment such as a tilt measure which can be preset to deliver a given volume. During all these operations the operator can be exposed to physical contact with both resin and curing agent and also to any vapours arising from them.

After mixing, the resin system is used in various ways. As an adhesive the mixed resin is applied to the surfaces being bonded, an operation which can involve considerable danger to the hands. In laminating the resin may be smeared over a moulding between layers of the appropriate laminating material. This is one of the most dangerous operations for contaminating the hands and it is perhaps fortunate that the high price of epoxy resins, among other things, has prevented their wide adoption for this type of work. In potting work the mixed resin is poured into a mould, usually metal but sometimes polythene or other suitable plastic, which may have been previously heated. With reasonable care, the hands need not be in contact in this operation, but there is considerable danger from vapour, especially using hot systems.

In all these applications the system may be hot- or cold-cured. Laminating systems are normally coldcured, but if heat is required it is normally applied by means of heaters built into the mould. Pressure may be used in this case also, and this may be applied by means of a vacuum bag technique. In this case any vapour coming from the system will be sucked off through the vacuum pump and may be discharged at a point quite remote from the mould. Adhesive and casting systems are also hot- or coldcured. For cold-curing the system is simply left aside for the appropriate time for curing to take place. Hot-curing in both cases is normally carried out in an oven. In this case, unless the oven is fitted with efficient extraction, there may be a considerable concentration of volatile fumes in the oven. Operators opening such ovens will be exposed to these hot vapours. It is important that extracted fumes from curing ovens are discharged clear of any employees.

When cure is complete the product is removed from the oven and/or the mould. At this stage the system is handled. This should be a safe procedure, but in certain cold systems a film of unreacted curing agent may be present on the surface when it comes in contact with the air. Further, cured systems may be subjected to machining, an operation which is generally regarded as safe, but in view of the possibility of unreacted curing agent being still present, this is open to question and will be discussed again later.
On the chemical side it should be noted also that many modifying agents such as fillers and plasticizers may be incorporated into the resin system, particularly in casting and laminating work. Some of these, such as mica, silica flour, and fibreglass materials, may have health hazards in themselves, to which appropriate attention should be given.

One last application which has not been discussed above is the use of epoxy resins in paints. So far no serious trouble has been encountered in this field, probably due to the low reactivity of the hardeners employed, but care should be exercised since essentially chemically active substances are involved, and in application these are present in solvents which may readily penetrate the skin, carrying resin and curing agent with them. A recent addition to this group is a pitch-epoxy resin surface coating which, it is claimed, is cold cured with normal amine curing agents. A solution of diethylene triamine in secondary butanol is claimed to give good results. This system is being recommended for brush or spray application to such items as pipes and tanks. As the amine hardeners are known as a serious dermatitis risk, and in this case they are present in a volatile solvent, extensive precautionary measures will undoubtedly be necessary, particularly with spray applications.

\section{Experimental}

It was decided to investigate the possible cause of dermatitis in the more commonly used mixtures particularly with regard to the amounts of amine used, as all suppliers recommend the provision of larger amounts of these than appears absolutely necessary to harden the resin. As one of the commonly used resins contains an unspecified plasticizer, this may have been of considerable influence in increasing the risk. It is also generally accepted that some of the many by-products which may result from these combinations may be the cause of some cases of dermatitis, but from previous experience it was likely that unused amine could be the most potent hazard.

Resin triethylene tetramine (" $D$ "/T.E.T.) mixtures were prepared under normal factory conditions. These were then de-aerated until no bubbles were seen to emerge from the mixtures. Small amounts were then spread on microscope slides. The $p \mathrm{H}$ of these mixes is about 10 to 11 . Some of the slides were allowed to harden in air, others were placed in ovens at $60^{\circ} \mathrm{C}$. It was found that all air-dried mixtures were of groundglass appearance whereas those stoved were much clearer, some being transparent. On microscopic examination the ground-glass appearance (Fig. 1) was due to circular bubbles of two types, some appearing to have a denser opaque centre and others fairly clear as if gaseous (Fig. 2). As resin D is known to contain a plasticizer (possibly di-octylphthalate), resin from another supplier containing no plasticizer was mixed with T.E.T. and examined after stoving; the result was a film 


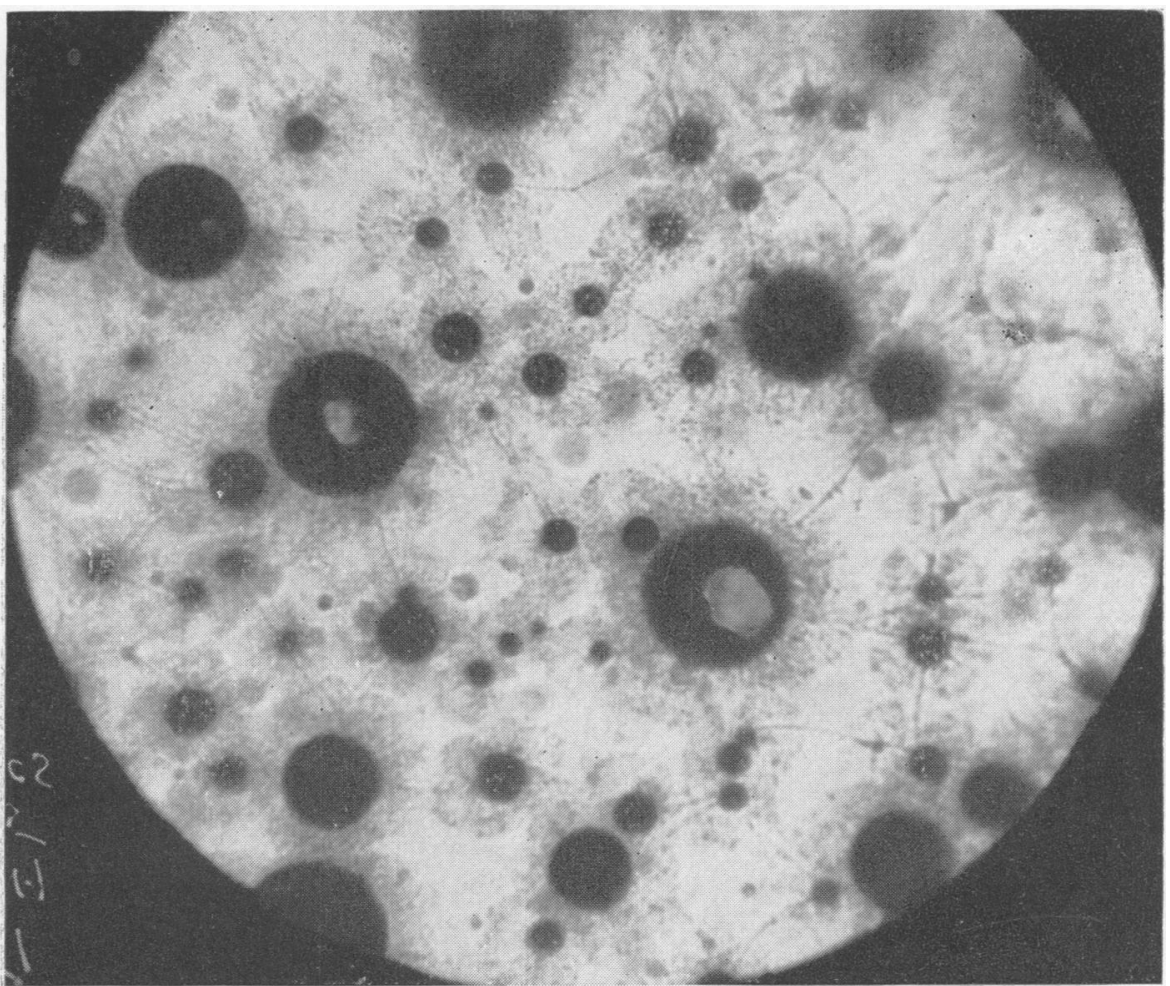

Fig. 4.-Resin “D”/T.E.T. to suppliers' recommendation. Stained MEK/Leishman. $\times 300$.

surprisingly free from bubbles, in fact, only one was found with difficulty (Fig. 3).

A simple technique for identification of the bubbles was desirable. Highly technical methods such as microscopic spectroscopy were not available. Biological staining technique offered a possibility if the resin films could be softened enough to permit staining. Methyl ethyl ketone (MEK) to which eosin acid (E. Gurr) was added to give a $p \mathrm{H}$ of 4 was found to be satisfactory. A film of "D"/T.E.T. was covered with the staining solution for 24 hours and it was found to be hard and had become stained red. Staining with a basic (MEK+ methylene blue $+\mathrm{KOH}, p \mathrm{H}$ 11) stain had no effect but an MEK/Leishman stain on a similar film gave a surprising result with only the acid stain being absorbed (Fig. 4). The results reveal that the films stain readily with acid stains. As hardened films of all resins with T.E.T. hardener, when tested with wet universal indicator papers gave a $p \mathbf{H}$ of at least 9 , it was decided to test mixtures under varying conditions with the results set out in Table 1 .

All mixtures were de-aerated and allowed to stand for three days after hardening.

All air-cured materials gave a mottled ground-glass appearance. These were retested one week later with similar results.

As the high $p \mathrm{H}$ of the hardened resins may have been
TABLE 1

RESULTS WITH 828/T.E.T. MIXTURE

\begin{tabular}{|c|c|c|}
\hline Mixture No. & Condition & $p \mathrm{H}$ \\
\hline $\begin{array}{l}1 \\
2 \\
3 \\
4\end{array}$ & $\begin{array}{l}\text { Room air cure } \\
\text { Dry air cure (in dessicator) } \\
\text { Moist air cure (rel. humidity } 100 \% \text { ) } \\
\text { Oven cure }\end{array}$ & $\begin{array}{r}10 \\
10 \\
11 \\
8\end{array}$ \\
\hline
\end{tabular}

due to excess amounts of amine hardener, mixtures were prepared containing both less and more than the suppliers' specification. If a true chemical combination took place then small amounts of amine were likely to be absorbed in the reaction. Twelve specimens were prepared as in Table 2.

TABLE 2

COMPOSITION OF 12 SPECIMENS OF RESIN “ D" AND T.E.T.

\begin{tabular}{c|c|c}
\hline Mixture No. & Resin “ D " (parts) & T.E.T. (parts) \\
\hline 1a & 24 & 3 \\
$2 \mathrm{a}$ & 27 & 3 \\
$3 \mathrm{a}$ & 30 & 3 \\
$4 \mathrm{a}$ & 33 & 3 \\
$5 \mathrm{a}$ & 36 & 3 \\
$6 \mathrm{a}$ & 42 & 3 \\
\hline
\end{tabular}

These specimens were mixed in air, de-aerated, and cured in dust-free air. 


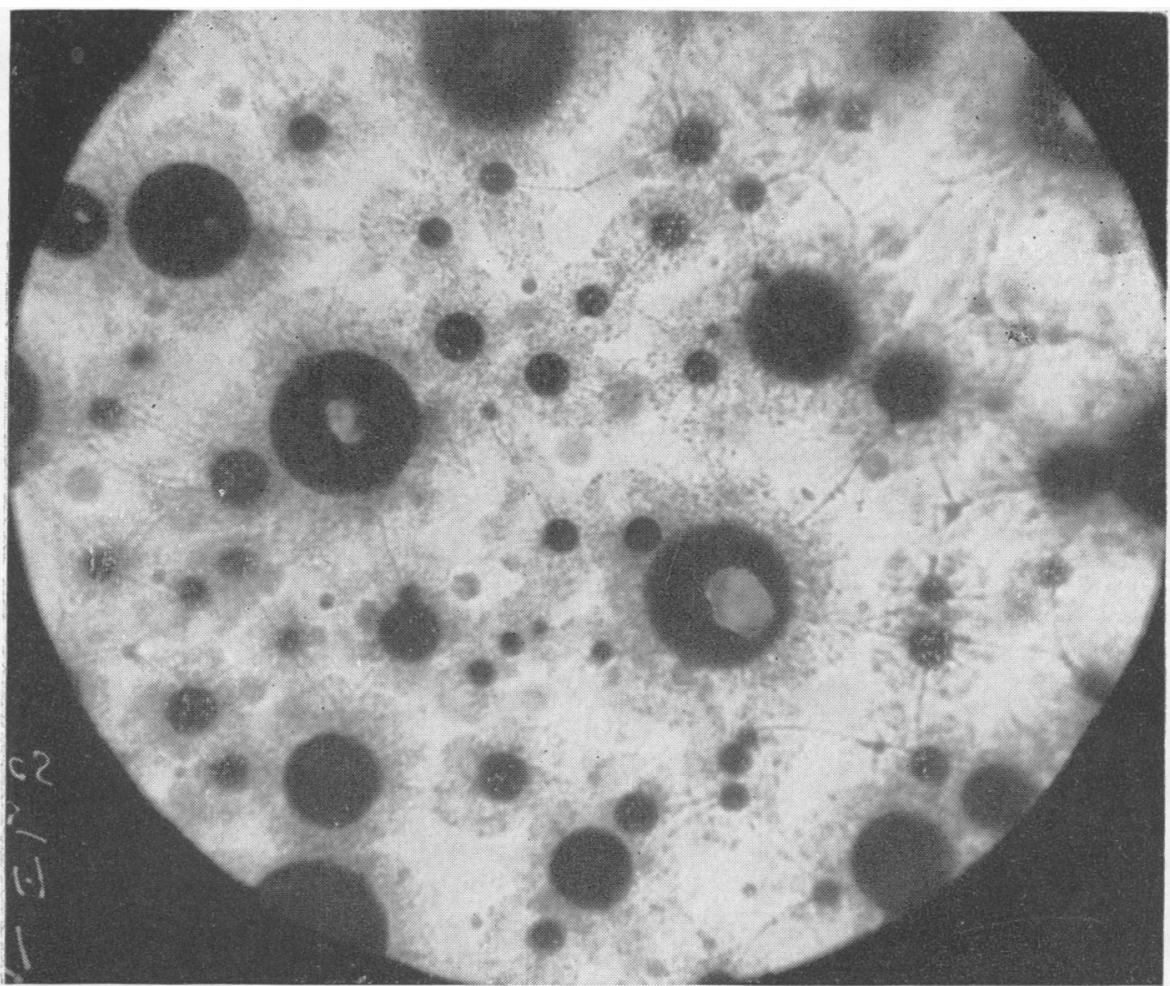

Fig. 4.-Resin “D”/T.E.T. to suppliers' recommendation. Stained MEK/Leishman. $\times 300$.

surprisingly free from bubbles, in fact, only one was found with difficulty (Fig. 3).

A simple technique for identification of the bubbles was desirable. Highly technical methods such as microscopic spectroscopy were not available. Biological staining technique offered a possibility if the resin films could be softened enough to permit staining. Methyl ethyl ketone (MEK) to which eosin acid (E. Gurr) was added to give a $p \mathrm{H}$ of 4 was found to be satisfactory. A film of "D"/T.E.T. was covered with the staining solution for 24 hours and it was found to be hard and had become stained red. Staining with a basic (MEK +methylene blue $+\mathrm{KOH}, p \mathrm{H} 11)$ stain had no effect but an MEK/Leishman stain on a similar film gave a surprising result with only the acid stain being absorbed (Fig. 4). The results reveal that the films stain readily with acid stains. As hardened films of all resins with T.E.T. hardener, when tested with wet universal indicator papers gave a $p \mathrm{H}$ of at least 9 , it was decided to test mixtures under varying conditions with the results set out in Table 1.

All mixtures were de-aerated and allowed to stand for three days after hardening.

All air-cured materials gave a mottled ground-glass appearance. These were retested one week later with similar results.

As the high $p \mathrm{H}$ of the hardened resins may have been
TABLE 1

RESULTS WITH 828/T.E.T. MIXTURE

\begin{tabular}{c|l|r}
\hline Mixture No. & \multicolumn{1}{|c}{ Condition } & $p \mathbf{H}$ \\
\hline 1 & Room air cure & 10 \\
2 & $\begin{array}{l}\text { Dry air cure (in dessicator) } \\
\text { Moist air cure (rel. humidity 100\%) }\end{array}$ & 10 \\
4 & $\begin{array}{l}11 \\
\text { Oven cure }\end{array}$ & $\mathbf{8}$ \\
\hline
\end{tabular}

due to excess amounts of amine hardener, mixtures were prepared containing both less and more than the suppliers' specification. If a true chemical combination took place then small amounts of amine were likely to be absorbed in the reaction. Twelve specimens were prepared as in Table 2.

TABLE 2

COMPOSITION OF 12 SPECIMENS OF RESIN “D” AND T.E.T.

\begin{tabular}{c|c|c}
\hline Mixture No. & Resin “ D" (parts) & T.E.T. (parts) \\
\cline { 2 - 3 } $1 \mathrm{a}$ & 24 & 3 \\
$2 \mathrm{a}$ & 27 & 3 \\
$3 \mathrm{a}$ & 30 & 3 \\
$4 \mathrm{a}$ & 33 & 3 \\
$5 \mathrm{a}$ & 36 & 3 \\
$6 \mathrm{a}$ & 42 & 3 \\
\hline
\end{tabular}

These specimens were mixed in air, de-aerated, and cured in dust-free air. 


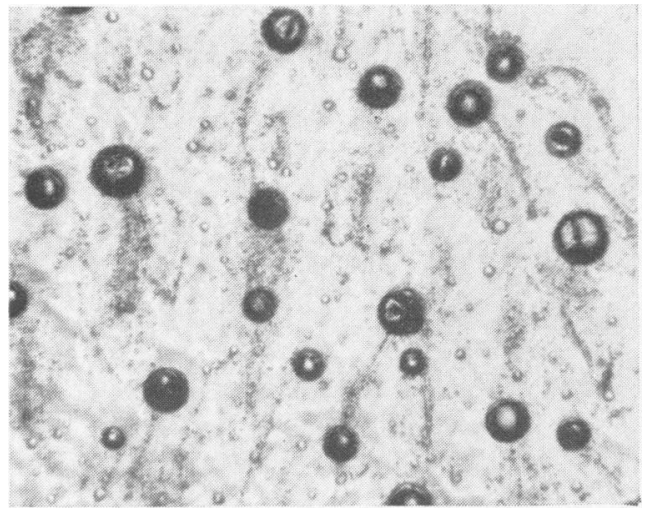

FIG. 5.-Mixture 1a.

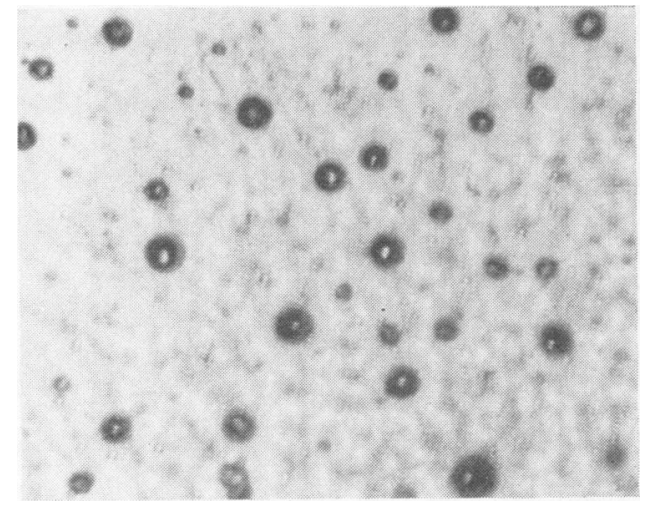

Fig. 7.-Mixture 2a.

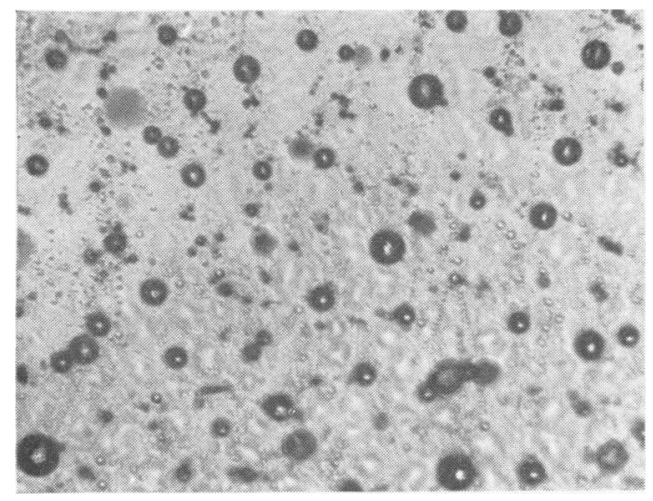

FIG. 9.-Mixture 3a.

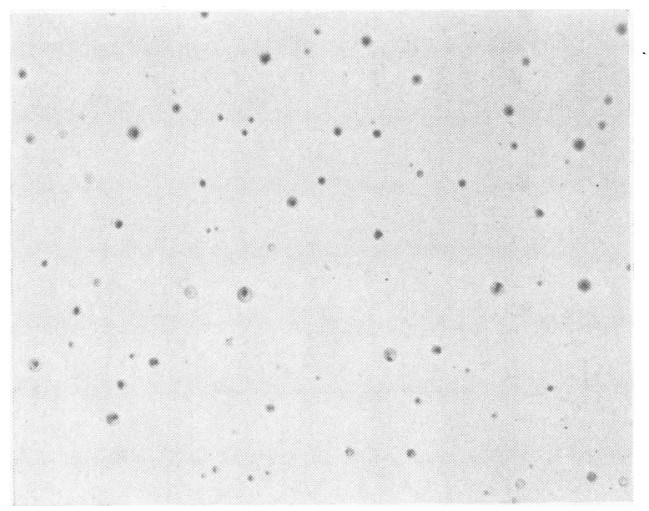

FIG. 6.-Mixture 1b.

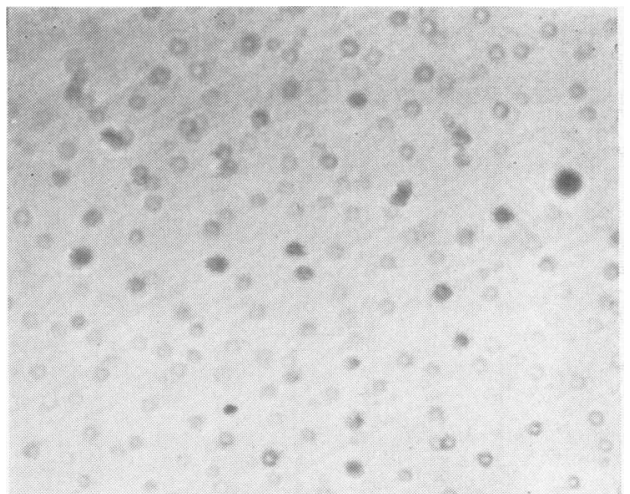

Fig. 8.-Mixture 2b.

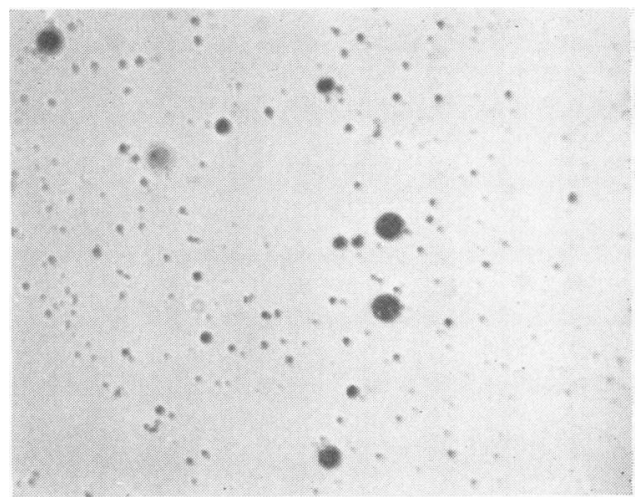

FIG. 10.-Mixture 3b. 


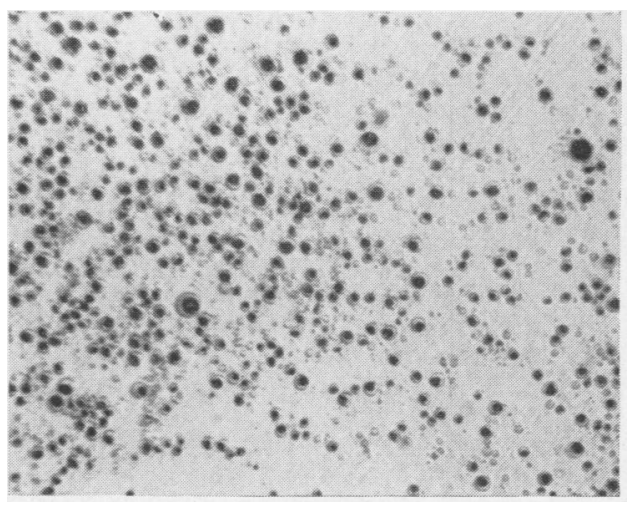

Fig. 11.-Mixture 4a.

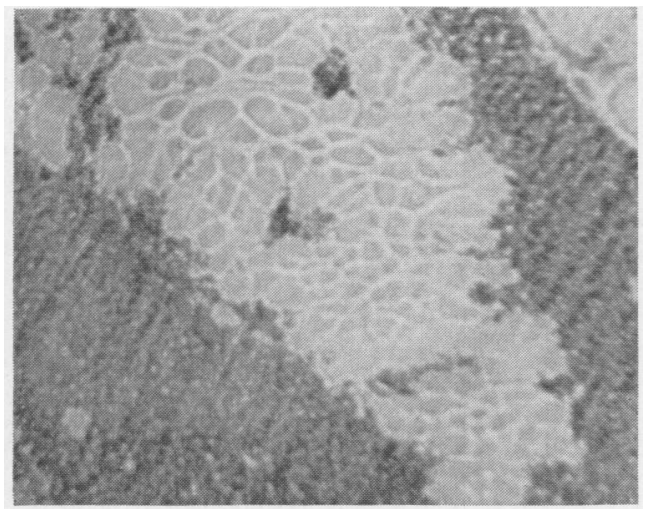

FIG. 13.-Mixture 5a.

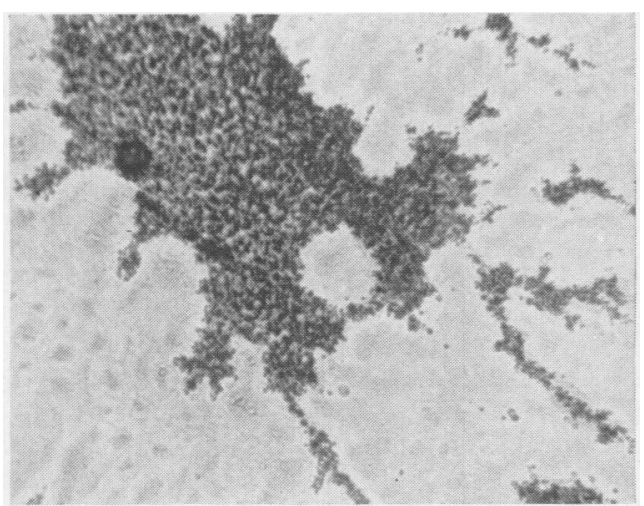

FIG. 15.-Mixture 6a

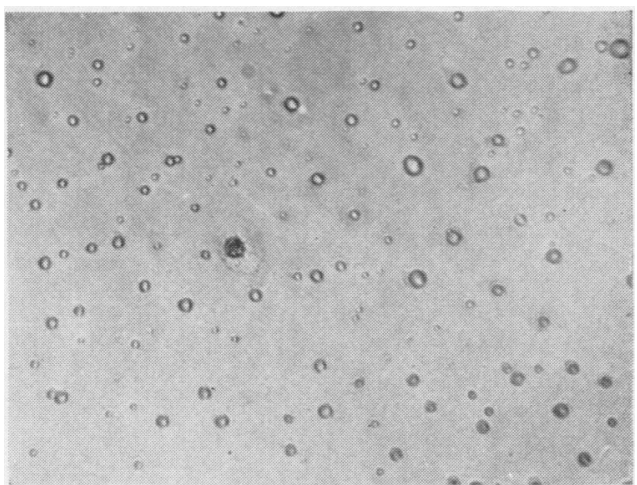

FIG. 12.-Mixture 4b.

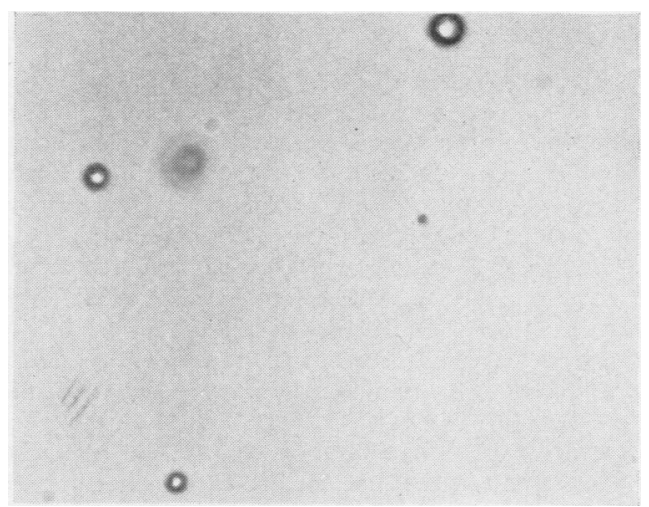

FIg. 14.-Mixture 5b.

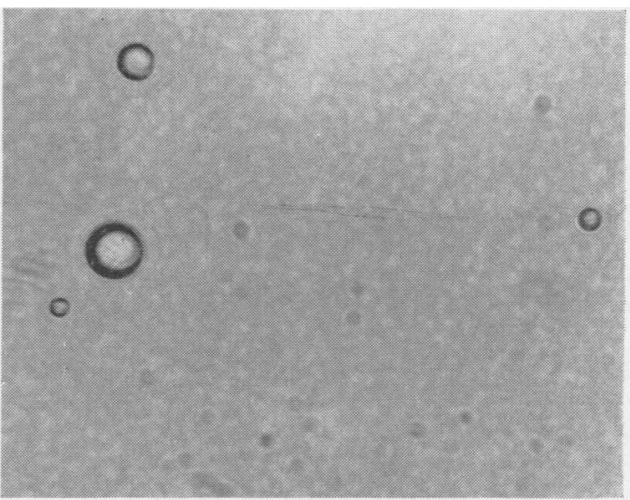

FIG. 16.-Mixture 6b. 


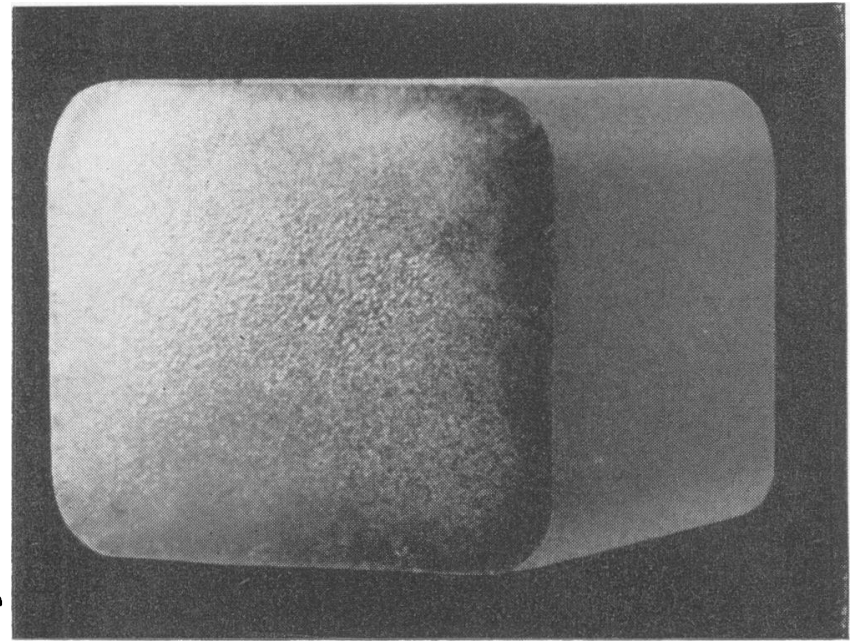

FIG. 17.-Greasy and finely pitted air-free surface of moulded block of " D"/T.E.T.

A similar set (mixtures 16 to 6 b) in the same proportions was prepared by 15 minutes' exposure to air, de-aeration, followed by cure at $60^{\circ} \mathrm{C}$. for one hour (1b to $6 \mathrm{~b}$ ). The only variant was the time between weighing and mixing.

In accordance with our previous findings, all air-cured specimens gave a mottled appearance and oven-cured specimens were clear. On microscopic examination in all cases bubbles were visible, but much reduced in the stoved specimens. It was also noticeable that as the amount of amine is reduced there were fewer bubbles visible (Figs. 14 to 16 ).

A further common finding is that when blocks of resin are formed in moulds, the air-free surface is found to be greasy and finely pitted (Fig. 17). The $p \mathrm{H}$ of this damp surface is about 12. The other surfaces of the moulded piece are dry and smooth.

As many of the mixtures include fillers such as mica dust or chalk, specimens of these mixtures were tested; they did not show bubbles although there were similar alkaline reactions at the air surface as noted above.

After six months the original cold-cured slides of resin-amine mixtures were again tested for alkalinity and in all cases a $\mathrm{pH}$ of $10+$ was demonstrated.

A cast block of " $D$ "/T.E.T. resin in the proportion of $10 / 1$ at least a year old was ground to powder and tested with hot extraction by acetone and water with the following results:

\section{RESIN SYSTEM D/T.E.T.}

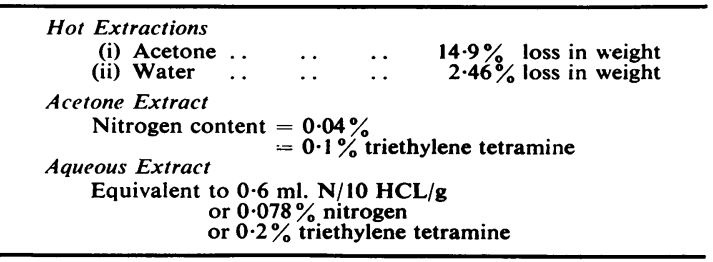

Conclusions.- The higher acetone extract is to be expected since it would contain low molecular weight polymers, unreacted resin, unreacted hardener, and plasticizer; whereas the water extract would leach out unreacted hardener and possibly only traces of the plasticizer and resin, together with water-soluble impurities of these.

Estimation of alkalinity on the aqueous extract and of nitrogen on the acetone extract indicated a free hardener content throughout the body of the cast resin of from 0.1 to $0.2 \%$ free amine.

Using a resin-hardener ratio of 10:1 this means that possibly $1 \%$ of the added amine remained in the body of the resin in the unreacted state.

\section{Physiological Effects}

Reports of the toxic effects on the alimentary canal tend to show that the risks of absorption here are small. It is of interest to note that these resins when fully polymerized have been used to coat the inside of food containers for some years without apparent harm to consumers.

Shell Chemicals Limited (1954) report that starved white mice were given epoxy resin $75 \%$ and $50 \%$ in dioctyl phthalate by the intragastric route in a syringe, first at room temperature in doses from $3.2 \mathrm{ml} . / \mathrm{kg}$. to $7 \cdot 1 \mathrm{ml} . / \mathrm{kg}$. and then at $37^{\circ} \mathrm{C}$. in doses from $13 \mathrm{ml} . / \mathrm{kg}$. to $30 \mathrm{ml} . / \mathrm{kg}$. without ill effect. In a further experiment to test subacute toxicity, the same mixtures and an epoxy resin $100 \%$ were added to the diets of male rats for 26 weeks and no gross or histological abnormality was seen in liver, lung, heart, kidney, stomach, intestine, or bladder. The only positive finding was that the ingestion of resin amounting to $1 \%$ of the diet caused a weight loss.

Hine et al. (1956), in a series of animal experiments to test the effects of epoxy resins, administered glycidol and five related ethers to animals and found that in addition to other systemic effects, the central nervous system was depressed on intragastric administration.

Bakelite Limited (1957) have issued the following report of work done at the Mellon Institute, Pittsburg:-

" A summary of our laboratory results with ZZLB0814 hardener is as follows. When administered to rats by mouth, this product has an $\mathrm{LD}_{50}$ dose of 5.6 grams per kilogram body weight. As a matter of interest this is in the same general quantitative range of oral toxicity for the rat as lactic acid, n-hexanol or oil of citronella."

Another American Company, General Mills (1957), state that their "polyamide catalyst ('versamid 125 ') was fed to albino rats and that the acute oral mean lethal dose $\left(\mathrm{LD}_{50}\right)$ is greater than $8.0 \mathrm{~g} . / \mathrm{kg}$. This material is relatively non-toxic by the oral route". They also state that this com- 
pound is not a sensitizing agent in the albino guineapig and that " these materials can be considered to be practically non-toxic by the percutaneous route. A mild erythema is produced at the exposure site, but no signs of systemic toxicity are manifest ".

Pyridine is certainly toxic and is considered by some authorities to cause severe liver and kidney damage in addition to other pathological effects (Browning, 1953). There is unlikely to be much risk of direct ingestion of these materials during work, and, in view of the evidence quoted, accidental ingestion should not result in toxic sequelae.*

A much greater hazard results from exposure to volatile curing agents. Pyridine if inhaled has an irritant effect on mucous membranes, the respiratory tract, and conjunctivae (Jacobs, 1941). Piperidine (hexahydropyridine) is suspect, as the British Pharmacopoeia notes that it has a coniine-like action. Aniline formaldehyde (A.F.) resins added to epoxy resins give useful commercial products but the mixing of the two compounds may possibly produce an irritant vapour as the required temperature for reaction is 100 to $120^{\circ} \mathrm{C}$. when the A.F. resin is stirred into the hot epoxy resin.

Of all the curing agents T.E.T. is the one which has been found to cause most trouble. Grandjean (1957) tested the concentration of T.E.T. at head level at room temperature in a factory where epoxy/ T.E.T. mixtures were being used throughout the day and found that " at a normal work bench the average concentration of T.E.T. vapour at head level is below the limit of measurement of $0.15 \mu \mathrm{g}$./l. air ". This may be true of the conditions examined by Grandjean, but where relatively large amounts of these materials are used such as in castings up to half a ton, an experienced authority (Pentz, 1957) has expressed the opinion that " in our experience a considerable part of the dermatitis that has arisen has in fact been caused rather by vapour than by liquid contact and, further, the liquid epoxide resins, though less troublesome than liquid amine hardeners, are themselves not to be regarded as innocuous".

A common symptom is erythema of the face with oedema of the peri-orbital regions and marked pruritus resulting from hot vapour escaping from ovens in which trays of small parts treated with resin are being baked. The operator usually places trays of work in these ovens without taking precautions to guard the face. Indirect exposure to the vapour as a result of convection currents at a distance from the actual process has caused many cases. If the vapour is inspired attacks of coughing develop which may be followed by temporary

\footnotetext{
* Pletscher and his colleagues (1954) reported signs of functional disorder of the liver, which they attributed to the action of hardeners, but this result has not been confirmed elsewhere.
}

respiratory distress but no permanent damage to the respiratory tract results. Intermittent exposure causes a return of the symptoms which, in most cases, subside when the sufferer ceases work, and there is usually no discomfort by next morning. Dernehl (1951) noted an allergic effect on the respiratory tract from ethylene amines but Savitt (1955) was not able to corroborate these findings as to the asthma-like reactions after continuous exposure with similar amines. We have not met any cases presenting asthmatic symptoms but, by analogy with other volatile chemicals, asthma would appear likely to develop in susceptible subjects. We have not seen any lesions of the nasal or buccal mucous membranes.

The results of skin contact have given the most trouble and the first symptoms, whether caused by vapour or direct primary contact from the resin or curing agent mixture or the curing agent alone, are similar to those of most volatile industrial irritants. Physiological activity appears to have a direct relationship with physical and chemical activity. From the hot vapour as previously noted, there is marked pruritus and erythema and oedema. The first effect may be immediate or delayed for some days. This may settle down and clear, but on return to exposure the reaction is likely to recur in most people, usually within hours or days and be more severe causing a generalized erythema with oedema of the face, particularly of the peri-orbital regions, and also a marked conjunctivitis. Excoriations of the backs of the hands are commonly seen. In other cases where there is a history of splashes, vesicles or bullae may form, or a punctate erythema may develop with marked folliculitis to be followed by an exfoliative dermatitis.

Resin or amine contamination in the nail regions may result in paronychia. Splashes harden on the skin and physical removal often causes trauma to the keratin. Care must be taken not to transfer any contaminant to unprotected areas of the body, as in a case previously described (Bourne, 1957), in which a man although fully protected with barrier cream on the hands and with no record of symptoms, left his work place to urinate without washing his hands and conveyed some of the mixture to his penis with unfortunate results. A similar case has recently been seen in an unprotected research chemist.

Perspiration increases the risk and is likely to intensify the symptoms. Dernehl (1951) in his series found that $80 \%$ of all personnel at risk reported dermatitis within three years and most cases (66\%) occurred in the hot months. He was of the opinion that both irritative and allergic phenomena are active. 
Savitt (1955) painted undiluted amine on the skin of the belly of rabbits and reported " severe corrosive reaction with toxic effect". When he diluted the amine to $10 \%$ in water, the skin reaction was eliminated. This does not appear to be a satisfactory criterion as the amines are used undiluted in industry.

As previously pointed out, the reaction between an epoxy resin and curing agent is exothermic and may be considerable, as much as 60 calories per gram being generated, but in common with other observers we have not as yet noted any skin burns from this.

In general the amines may be classified as direct primary irritants and also may act as secondary sensitizers. Cross sensitization with other amines has been noted in laboratory workers where shortterm exposures to many amines are usual and also in factories where a process has been changed. It is generally held that the epoxy resins are less liable to cause skin reactions, but Hine and his colleagues (Hine et al., 1956) found that glycidol and the glycidyl ethers cause irritation of the skin ranging from erythema to eschar on cutaneous application, but all produced some irritation.

Attention has been drawn to the greasy pitted appearance of the air-free surface of moulded blocks of resin and its high $p \mathrm{H}$. This film disappears when the surface is subjected to heat but returns when the resin recools and eventually may disappear altogether on repeated heating. This surface effect may well have been the cause of dermatitis in a patient with a prosthesis made of a resin-amine mixture.

A man with a partially amputated arm was fitted with a prosthesis made of epoxy resin-amine lamination. A few days after, a severe dermatitis developed in the stump, significantly in an area where some patching with resin had been carried out after the original casting. The prosthesis was then restoved for three days at $80^{\circ} \mathrm{C}$. and was reapplied to the limb after the dermatitis had cleared. No further skin reaction was experienced. The exudate of high $p \mathrm{H}$ material may well have been the cause of dermatitis in this case.

The working of the finished resin product does cause serious problems, particularly where employees have become sensitized. The fine dust which arises when laminates or castings are machined, drilled, sandpapered, or filed causes marked irritation or erythema of the mucous membranes and skin in spite of the opinions expressed by the suppliers of the raw materials that the so-called polymerized epoxy resin is safe.

A research engineer contracted dermatitis in developing new combinations of epoxy-amines, became generally sensitized, and is now highly reactive to minute quantities in the atmosphere of any part of the resin mixture in any stage, cured or uncured, and if he enters a laboratory or shop where the finished product has been worked he flares up in under a minute. At one period he developed an acute psychosis as a result of the pruritus and had to be treated in a psychiatric hospital.

A manufacturer of sports equipment purchased rod sheet and fibre glass laminates of epoxy resin for use in making tennis racquet frames, golf club handles, etc. During the machining and working of this material, cases of dermatitis developed in practically all those at risk as a result of the powder given off by the material.

Phenylene diamines have been recommended, particularly metaphenylene diamine, which is used where special heat-resisting polymers are required. In this process the meta-phenylene diamine in powder is heated until it is molten and then mixed with the resin. The whole operation should be carried out in a fume cupboard, as the metaphenylene diamine sublimes, contaminates the atmosphere, and settles on neighbouring objects and eventually causes brown staining of the skin but no irritation. It should be noted that the phenylene diamines, toluene diamines, and other alkylated benzene diamines and the salts of these compounds are included in the schedules of the Poisons List (1949) and the Poison Rules (1949). Of these compounds para-phenylene diamine is in general use as a hair dye and is known to cause dermatitis occasionally in susceptible subjects.

An interesting case of systemic poisoning resulting in death from subacute atrophy of the liver in a female hairdresser's assistant aged 21 was reported by Israëls and Susman (1934). In this case there appears to have been no skin disease attributable directly to the para-phenylene diamine. Rubber gloves were used to apply the dye and the gloves were removed for the shampoo which followed. The stained hands were treated with hydrogen peroxide and this was considered to be a possible contributory cause of death.

Occasionally workers have been seen who have had resin or amine splashes on the unprotected skin and have not reported any ill effects. There are also those who develop mild attacks of transient erythema and minimal eczematous lesions of the hands, who, when the skin has cleared, continue epoxy resin work without further involvement. This " hardening" effect has been reported in many chemical workers but in epoxy-amine processes appears to be much less common. Hellier (1958) has suggested that hardening may be due to an " immunological process or may simply be the result of mechanical toughening of the skin ". 


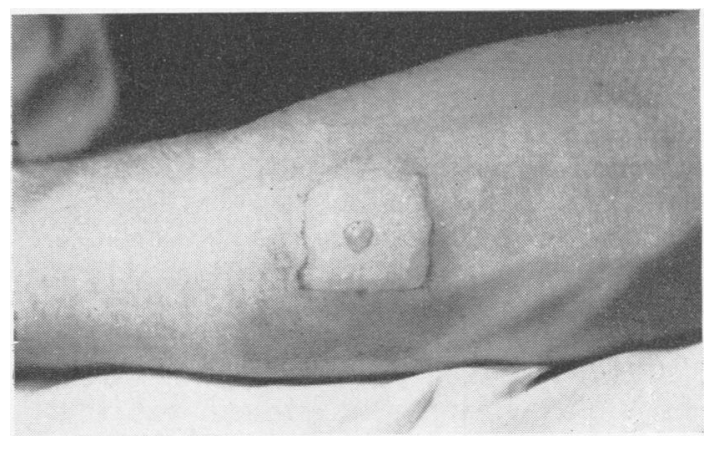

FIG. 18.-Bulla from patch test with ethylene amine.

Prophetic patch testing in the selection of staff appears to us to be of no value. A positive reaction may be expected in practically all those who are submitted to the amines in the strengths used in these processes. As long ago as 1949 one of us (L.B.B.) submitted a worker to a test with the smallest possible amount of an ethylene amine with the result shown in Fig. 18. The bulla formed rapidly, took several weeks to heal, and left a permanent scar.

Patch testing in those who have dermatitis from resins is in our opinion indefensible. Malten (1956), investigating the effects of epoxy resins, carried out an extensive series of patch tests in Holland. In all 157 substances used in plastics were tried in varying concentrations. The results were not convincing, but he did conclude that "workers making and using synthetic resins formed by polycondensation are exposed to greater occupational hazards than those working with synthetic resins formed by polymerization ". The results of all patch testing are notoriously variable and Von Haam and Mallette (1955), investigating the effects of plastics, found that " their previously published results with 90 irritating compounds are probably erroneous and are retesting all those showing positive reactions".

Lauer (1956) has summarized the position of the industrial physician adequately as follows:

"Preplacement patch tests with substances encountered in the occupation have been advocated but the author does not subscribe to routine preplacement patch testing, because if the worker has never come into contact with them, careful questioning should elicit his hypersensitiveness. Patch tests may give negative results but will not foretell whether the person will become sensitized with this substance."

Splashes in the eyes cause acute pain and conjunctivitis. Savitt (1955) applied ethylenediamine and diethylenetriamine to the eyes of rabbits and caused severe corneal damage. Similar effects occurred when the same substances were diluted to
$15 \%$ in water, but a $5 \%$ dilution caused only minor injury. Employees occasionally complain of inability to focus and a halo effect around objects focused upon.

There were no signs of other central nervous system involvement, difficulties of respiration (other than those already noted), or of gastric upset, but the results of Hine et al. must be considered when cases of long-term exposure are eventually investigated.

As many specifications include the use of fillers which are added to the resin mixture, commonly chalk, mica flour, and silicates, care must be exercised in the mixing, as the continuous inhalation of silicates may cause lung disease and it would be a wise precaution to use only large mesh size powders.

Headache is commonly complained of but is usually transient.

We have not seen nor are we aware of reports of neoplastic skin changes from epoxy resins or amines, although it has been suggested, as a result of the work of Hendry, Homer, Rose, and Walpole (1951), that bis-epoxides may be carcinogenic, but it must be pointed out that they worked with considerably higher molecular weight chemicals than those in use in the resins we are considering. Whitby (1957), who has studied these resins for a considerable time, is of the opinion that the molecular weight of a resin is important in relation to its toxicity and that the commercially available resins are much less soluble in body fluids than those used by Hendry and his associates. He also considers that "when the resin is cured by higher polymerization and cross linkage the irritant effect goes down enormously".

\section{Incidence}

There are now reports to show that in unprotected workers a very high incidence may be expected. In the U.S.A. it has been stated (Borden Co., 1955) that " epoxy resins and amine hardeners are the greatest single source of contact dermatitis in industry today". An experienced industrial physician who visited several factories in the U.S.A. reported: "In $1954 \mathrm{I}$ was in several factories in the States where motor car bodies were being made with epoxy resins and in these it was common for the occupiers to admit to a $75 \%$ incidence of dermatitis, but while walking round it was very difficult to see anyone who was not showing signs of dermatitis of the hands, arms or face, so I would put the incidence nearer to $100 \% "$ (Reynard, 1958).

Grandjean (1957) reported an incidence of $50 \%$ in 328 workers in factories in four countries. Reports of considerable involvement are available from most European countries. Malten (1956), in his survey in Holland, reports a high incidence after investi- 
gating all the known substances with which the workers came into contact. In Great Britain there have been many cases and compensation has already been awarded by the High Court for dermatitis from this cause. Actual figures are not available, but in the factories inspected by us the incidence of those at risk has varied from $100 \%$ down to $20 \%$.

\section{Discussion}

There is no doubt that epoxy resins/amine curing systems can now be considered as toxic. Amines are more chemically reactive than epoxy resins and are capable of producing considerable pathological disturbance although the resins are less likely to do so. The resin/amine systems do not form completely polymerized inert products and in the course of curing produce volatile materials which may cause dermatitis, inflammation of the mucous membranes, skin allergies, less commonly respiratory distress, and occasionally other symptoms such as liver dysfunction or visual disturbance. Ingestion of the resin, which is unlikely in industry, has been tested in animals and appears to have caused little upset, but although there are no reports of ingestion of amines in man it is likely that severe poisoning would result. There are no reports of carcinogenic activity in the industrial field, but the suggestion has been made that such activity is possible. Blood disorders have not been noted. Delay in the development of symptoms varies from hours to weeks after exposure and cross sensitization to other compounds in epoxy/amine systems is frequent. The sensitization may last for long periods.

Examination of the cured resin confirms that there is a complex chemical mixture formed which may consist of reacted or unreacted amines, plasticizers where used, and many possible unidentified intermediate products as the result of the interaction of the components of the system.

Plasticizers appear to play some part, as resin systems which do not use them produce far fewer bubbles. The products of all the systems produce materials with relatively high $p \mathrm{H}$ levels and these values remain for long periods. The greasy air surface of cast blocks may be an exudate of unreacted amine or other organic material of high $p \mathrm{H}$. Extraction of amine from the so-called polymerised resin gives a relatively high percentage of amine in unreacted state. Amines are well known as primary skin irritants and also as sensitizers (Schwartz, Tulipan, and Birmingham, 1957), and, as in all the specifications the amine values are relatively high, these will, in our opinion, account for most of the cases of contact dermatitis. The hot amine vapour emitted during curing operations attacks the con- junctivae and the more sensitive skin of the face, as would be expected.

Although varying the concentrations of amine in a resin/amine mixture does not appear to alter the appearance of the finished product, it was surprising to find that amine concentrations as low as $1: 14$ produced a film showing large amounts of unreacted material (Fig. 15) with a relatively high surface $p \mathrm{H}$ value which would be likely to be as great a risk as mixtures containing larger amounts of amine. The plasticizer may be in part responsible for this. As most of the dermatitis cases seen were caused by the use of this resin, there is no doubt that more care must be exercised in its use. The heat treatment of the resin/amine system markedly reduced the surface $p \mathrm{H}$ and within the body of the resulting product there were fewer bubbles. Atmospheric conditions appear to be of importance in cold cures as mixtures allowed to harden in high relative humidity gave the highest $p \mathrm{H}$ recorded $(11+)$.

The cases of dermatitis and sensitization which have resulted from the working of hardened resin (by sawing, filing, etc.) are not surprising as the fine powder may contain $1 \%$ of amine in the unreacted state. The heat developed by the fast moving tool will tend to increase the liberation of unreacted volatile materials. The sensitization of the mucous membrane of the nasal mucosa and conjunctivae is acute and may be profoundly disturbing.

In view of the known risk from amines, the replacement of these by amides is desirable in those factories where trouble-free and no-touch techniques cannot be introduced. On the evidence of freedom from bubbles in the mixtures this would be justified.

The epoxy resins and glycidyl compounds are possible hazards, but appear to be less likely to cause trouble if handled with reasonable care. As it is possible to meet most of the demands of industry with resins not containing plasticizers there seems to be no object in their general use. Nevertheless, as indicated above, the substances of which epoxy resin is composed, i.e., epichlorhydrin and diphenylolpropane, are both irritants (Hine et al., 1956) and we have been informed (Narracott, 1953) that it is possible for chemical manufacturers to produce these and combine them by modern installations with little risk to the process workers.

A confirmation of our finding that air-cured resins are likely to be more harmful to the skin is given in a recent report by Gaul (1957) who in investigating dermatitis due to epoxy resin with phthalic anhydride hardener came to the following conclusions:

"A fresh sample of air cured resin was as allergenic as the liquid resin. This appears to indicate that the use of air cured epoxy resins could lead to nurierous 
sources of sensitization. Liquid epoxy resin proved to be the allergen with the sensitizing component directed to the bisphenol A. The patch test reactions were almost perfect reproductions of the irritation from adhesive tape."

Gaul carried out patch tests with $1 \%$ concentrations in olive oil. This, we think, can lead to difficulties in interpretation. In any case, the concentrations bear no relationship to actual use and although he tested T.E.T., butyl phthalate, and phthalic anhydride with negative results, this may have been due to dispersion of the allergen or retardation of absorption through the use of olive oil. We have seen similar negative results when paraffin molle was used with amines and epoxy resin although it is certain in Gaul's case that the man tested had dermatitis while using these chemicals.

It seems that much of the trouble caused by the introduction of the epoxy resins and amine and amide hardeners into industry has resulted from the failure of responsible authorities to recognize that they are dealing with highly reactive chemicals. There is some awareness that when resin and hardeners are mixed, a reaction takes place, but this reaction is often thought to be specific to the system involved, and the average users of these resins do not seem to realize that chemical activity and biological activity are inseparable. Indeed biological activity in this sense is merely a synonym for chemical activity in a biological system.

The chemical groupings associated with these systems,

the epoxy group<smiles>CC1(C)OC1(C)C</smiles>

and the polyamine group,<smiles>CC(C)NC(C)N</smiles>

are both highly reactive even at room temperature, as is shown by the use of compounds containing these groups in the so-called cold-curing processes.

There is therefore no a priori reason why either of these types of material should not enter into reaction with biological systems under the same mild conditions.

In the unpolymerized forms both the resins and the catalyst are materials of low molecular weight which are readily miscible with skin secretions and consequently can penetrate rapidly and easily into the sensitive lower layers of the skin; in addition, the volatility of the lower amines allows their entry into the body by ingestion and inhalation.

Once these reactive molecules have passed into the body in this way, it is reasonable to postulate a combination between them and the reactive groupings of a protein.

For example, the free epoxy end-group of a resin is known to react with phenols<smiles>CCCC1OCC1OCC(O)CC</smiles>

and a reaction can thus be imagined between the tyrosine residue of a protein and an epoxide resin.<smiles>CCC(O)COCCCCC(N)CC(=O)O</smiles>

A similar reaction might occur with amines and the reaction between an epoxy resin and the primary amine group of a catalyst is formally similar to that between the resin and the primary amine group associated with, say, the amine-acid lysine incorporated into a protein.

$$
\begin{aligned}
& -\mathrm{CH}_{2}-\mathrm{CH}-\mathrm{CH}_{2}+\mathrm{H}_{2} \mathrm{NR} \\
& \stackrel{\stackrel{\mathrm{OH}}{!}}{\rightarrow-\mathrm{CH}_{2}-\stackrel{\mathrm{CH}}{\mathrm{C}}-\mathrm{CH}_{2} \mathrm{NHR}}
\end{aligned}
$$

The amine catalysts themselves can also react with proteins where amino-acid residues carry terminal ester groups

$$
\begin{aligned}
-\mathrm{CH}_{2}-\mathrm{COOCH}_{3}+\mathrm{H}_{2} \mathrm{~N}-\mathrm{R} \\
\rightarrow-\mathrm{CH}_{2}-\mathrm{CO}-\mathrm{NHR}+\mathrm{CH}_{3} \mathrm{OH}
\end{aligned}
$$

Protein molecules modified in this way may possess the properties of antibodies and these may be responsible for the severe sensitization reactions often encountered in industrial exposure to the amines and hardeners.

This purely theoretical approach to the mechanism whereby these substances exert their physiological 
effects has the following important practical consequences:

(a) No resin and hardener system capable of reacting at normal temperatures can be regarded as physiologically inert.

(b) It is impossible to produce such a system which is completely non-toxic since chemical and biological activity are inseparable.

(c) Minimum toxicity should be associated: (i) with minimum volatility of the components; (ii) with minimum solubility in skin secretions.

(d) It seems to be an experimental fact that the risk of sensitizing an individual to these materials is proportional to the integrated exposure (concentration $\times$ time) to which he is subjected. Once an individual is sensitized, the slightest contact with the offending material will provoke an immediate reaction.

It follows that the risk of sensitization can be minimized if (1) pollution of the atmosphere is avoided. (2) The material is prevented from coming into contact with the skin. (3) Where contamination of the skin is unavoidable, suitable barrier cream should be used to minimize the risks of penetration. (4) Deposits of resin should not be allowed to accumulate upon the skin but should be cleaned off as frequently as circumstances permit.

Point (1) implies good ventilation technique. Special attention should be paid to ensuring that fresh air passes first over the worker then over the work, and then to the extraction system.

Point (2) requires the introduction of no-touch technique whenever possible.

Point (3) is now well recognized in industry and the manufacturers of resin recommend the use of barrier creams in their technical literature. These creams should be of the water-repellent type as aliphatic amines are water soluble and sweat penetrating through a water-soluble cream will leach the amine back into the skin.

Point (4) is much less well understood. The uncured or partially cured resins are readily soluble in such solvents as methyl ethyl ketone or toluene. This fact has led to the widespread use of such solvents for cleansing the skin. It is not fully realized, however, that apart from waste and fire risk this habit is extremely reprehensible from the point of view of industrial hygiene. The solvent may remove some of the contaminant but spreads the rest over the skin besides facilitating its penetration. The use of soap and water to remove resins is often recommended but simply does not work if the resin has been in contact with the skin for any length of time. Soap and water is equally ineffective in removing traces of resin after washing in solvents.

$A$ third and equally undesirable practice is to allow the resin to harden completely and then to pick it off the skin. This is an effective method of removing epidermis and renders the underlying skin even more vulnerable at the next contamination, particularly around the nails.

In an effort to solve this problem, a cleansing cream has been produced which combines solvent and detergent properties. Both the solvents and emulsifying agents used have been specially selected to give the minimum of dermatological offence.

The mechanism of action of the cream is as follows:

The solvent phase quickly dissolves the resin and the resulting solution is rapidly re-emulsified into the cream. Since the cream has an aqueous external phase, the solvent is not normally in contact with the skin either before or after picking up the contaminant. Furthermore, creams of this type are non-inflammable and any residues are compatible with soap and water.

The use of this cream is desirable even when the hazard of skin irritation is considered unimportant, since under production conditions, the impairment of manual dexterity due to an accumulation of resins on the skin is an important factor, as is the time wasted in inefficient methods of cleansing.

\section{Handling Precautions}

Experience has shown that it is now possible to avoid or reduce the hazards of these materials by efficient factory techniques. The ideal installation would be a complete no-touch system but this is usually not practicable. We have found that the following are essentials which can be applied to the smallest factories:

(1) Instruction and education of all staff.

(2) Only limited quantities of materials, particularly solvents, must be made available from stores. In practice this should be restricted to that amount necessary for the shift or at most for the day's work.

(3) A routine technique should be adopted so that one complete cycle of operation takes place, i.e., weighing, mixing, de-aerating, pouring, stoving.

(4) Mixing and de-aerating should take place in well-ventilated chambers under cowling or in fume cupboards. Extraction fans must discharge to the outside air. Hot processes should be totally enclosed. If possible the process should be housed in a special unit. Where exhaust ventilation is not possible, fans of reasonable size should be installed to blow air away from the operator.

(5) No smoking or consumption of food at work.

(6) Benches should have easily cleaned surfaces or covers which can be changed when soiled.

(7) For the cold (or air) cure process, work 
should be stored in well-ventilated chambers where restricted entry can be maintained.

(8) Paper cups which are frequently used to mix resins must be disposed of to avoid further contamination and are best destroyed by incineration outside the works.

(9) Full advantage must be taken of industrial hygiene: (a) Suitable barrier creams must be provided at the work bench and used regularly. (b) Resin-removing cream must be available at the work bench with a supply of clean rag or paper towels. (c) Protective clothing should be used and face masks if powders are used. Sleeveless overalls avoid impregnation of cuffs. (d) Good washing facilities on site.

(10) Pre-employment selection of workers to exclude those with a history of chronic skin disease, allergy, and asthma.

(11) All skin involvements and injuries should be reported immediately.

(12) Thorough cleansing of the hands before using lavatories.

\section{REFERENCES}

Bakelite Ltd. (1957). Technical Memoranda, June. London. Borden Co. (1955). Casco Service Bulletin No. 8a. New York.

Bourne, L. B. (1957). Practitioner, 179, 67.

Browning, E. (1953). Toxicity of Industrial Organic Solvents, rev. ed. 1952, p. 370. H.M. Stationery Office, London.

Dernehl, C. U. (1951). Industr. Med. Surg, 20, 541.
Gaul, L. E. (1957). J. invest. Derm., 29, 311.

General Mills (1957). Report on Non-Toxicity of Versamid Polyamide Resins, Kankakee, III.

Grandjean, E. (1957). Brit. J. industr. Med., 14, 1.

Hellier, F. F. (1958). Brit. med. J., 1, 196.

Hendry, J. A., Homer, R. F., Rose, F. L., and Walpole, A. L. (1951). Brit. J. Pharmacol., 6, 235. Hine, C. H., Kodama, J. K., Wellington, J. S., Dunlop, M. K., and Israëls, M. C. G., and Susman, W. (1934). Lancet, 1., 508.

Jacobs, M. B. (1941). The Analytical Chemistry of Industrial Poisons Hazards and Solvents, p. 573. Interscience, New York.

Lauer, D. J. (1956). Penn med. J., 59, 25.

Malten, K. E. (1956). Verh. Ned. Inst. Prev. Geneesk., 32.

Narracott, E. S. (1953). Brit. Plastics, 26, 120.

Pentz, P. G. (1957). Personal Communication.

Pletscher, A. Schuppli, R., and Reipert, R. (1954). Z. Unfallmed. Berufskr., 47, 163.

Reynard, W. J. (1958). Personal Communication.

Savitt, L. E. (1955). A.M.A. Arch. Derm. Syph., 71, 212.

Schwartz, L. Tulipan, L., and Birmingham, D. J. (1957). Occupational Diseases of the Skin, 3rd ed. London.

Shell Chemicals Tech. Bulletin (1954). May.

Von Haam, E., and Mallette, F. S. (1955). Amer. industr. Hyg. Ass. Quart., 16, 324.

Whitby, L. H. (1957). Personal Communication. 